\title{
Evaluation of Response Time in Monitoring System on the Accuracy of Recording Individual Feeding Behavior and Feed Intake in Dairy Cows
}

\author{
Rong Wang \\ Institute of Subtropical Agriculture Chinese Academy of Sciences \\ Cheng Gao \\ Chinese Academy of Agricultural Sciences Institute of Bast Fiber Crops \\ Min Wang ( $\nabla$ mwang@isa.ac.cn ) \\ institute of subtropical agriculture \\ Xiumin Zhang \\ Institute of Subtropical Agriculture Chinese Academy of Sciences

\section{Zhiyuan Ma} \\ Institute of Subtropical Agriculture Chinese Academy of Sciences \\ Duanqin Wu \\ Chinese Academy of Agricultural Sciences Institute of Bast Fiber Crops

\section{Zhongshan Wei} \\ Hunan Animal and Veterinary Science

\section{Zhicai Li} \\ Hunan Animal and Veterinary Science

\section{Shuai Gao} \\ Hunan Animal and Veterinary Science

\section{Zhiliang Tan} \\ Institute of Subtropical Agriculture Chinese Academy of Sciences
}

\section{Short report}

Keywords: monitoring system, feeding behavior, feed intake, respond time, visit

Posted Date: January 6th, 2021

DOI: https://doi.org/10.21203/rs.3.rs-139294/v1

License: (c) (i) This work is licensed under a Creative Commons Attribution 4.0 International License. Read Full License 


\section{Abstract}

Background: The advent of monitoring system can automatically collect the quantitative data of the feeding behavior and feed intake of individual cattle, and the immediate response system always records many non-eating visits. Increasing response time of trigger helps to decrease recording non-eating visits, but may also miss some small periods of recording feed intake. This study was to evaluate the effect of response time in monitoring system on the accuracy of recording individual feeding behavior and feed intake in dairy cows. The first experiment was to investigate the distribution of 10-h feeding behaviors of 8 Holstein dairy cows after morning feeding by using infra-red camera. The second experiment was to investigate accuracy of feed intake recorded by the monitoring system with different response times $(0.3,3,6,12$ and $24 \mathrm{~s})$ in comparison with direct weighting. The third experiment was to investigate effect of excluding the data of time interval after response time on feed intake and visiting behaviors recorded by the monitoring system, when responding time was set as $0.3 \mathrm{~s}$.

Results: The results showed that the most of eating and non-eating visits had duration larger than $24 \mathrm{~s}(99.0 \%)$ and less than $24 \mathrm{~s}(65.3 \%)$, respectively. Comparing with actual feed intake obtained by direct weighting, increasing response time greatly increased the recorded feed intake, with the greatest difference occurring at $6 \mathrm{~s}$ of response time $(P=0.001)$. Although increasing time interval after response time linearly increased mean, median feed intake per visit and 10-h feed intake $(P<0.01)$, it had little influence on 10 -h feed intake $(<0.1 \%)$ and eating visit $(<5 \%)$.

Conclusions: Setting immediate response $(0.3 \mathrm{~s})$ in monitoring system helps to get actual feed intake, but can obtain a lot of non-eating visits. Increasing response time helps to decrease the recording of non-eating visits, but can overestimate feed intake.

\section{Introduction}

Feeding behavior refers to the behaviors related to obtaining and consuming feed, and is an interesting area of research which links the nutritional and behavioral sciences. Such fundamental knowledge is essentially acquired to develop accurate feeding and explore development of algorithms for disease detection [1-4]. To our current knowledge, most of feeding behavior data has been obtained through direct visual observation or photogrammetry [5-7], both of which are labor intensive.

Recently, the electronic systems for monitoring feeding behavior and feed intake have been developed and validated [8-10]. The advent of monitoring system has enabled the collection of detailed, objective, quantitative data on the feeding behavior and feed intake of individual cattle [11]. The monitoring system is often equipped with an access gate that allows a specific cow to access a feed bin and two infra-red sensors with a very short response time that recorded the presence of a cow in the feeder [12]. The immediate response system always record many non-eating visits due to the accidental trigger of the cow, but can obtain actual feed intake. Increasing response time of trigger helps to decrease recording non-eating visits, but may miss some small periods of recording feed intake.

Our hypothesis was that unrecorded period of feed intake was not the major factor to influence accuracy of recording daily feed intake in monitoring system, when response time after trigger of cow was increased. The monitoring system used could automatically record feed behaviors, which included visiting behaviors and feed intake. Then, the present study was to investigate the effect of response time in monitoring system on the accuracy of recording eating and noneating visits, and feed intake. To achieve this goal, we conducted three experiments, which included estimating distribution of feeding behavior after feeding, comparing feed intake recorded by an automatic monitoring system versus direct weighting, and evaluating the effect of excluding the data of time interval after response time on visiting behaviors and feed intake. The video recording technique was used for visual observation and analysis.

Page $2 / 11$ 


\section{Materials And Methods}

All experimental procedures followed institutional guidelines for the care and use of animals and were approved by the Animal Care Committee, Institute of Subtropical Agriculture, the Chinese Academy of Sciences, Changsha, China. The experiment was conducted at Institute of Hunan Animal and Veterinary Science in the Chang-Sha County of Hunan Province, China.

\section{Monitoring system}

The monitoring system (Henan Nanshang Agriculture and Animal Husbandry Technology Co., Ltd., Nanyang, China) included mechanical device, electric identification, automatic weighting, data collection and storage, and remote feeding data extraction. Each feeder was equipped with an access gate that could allow specific cows to access a feed bin and two pairs of infra-red sensors that recorded the presence of a cow in the feeder. A visit started when the aerial in the access gate detected the presence of a cow that was allowed access to the feeder and the access gate was lowered. A visit ended when interruption of the infra-red sensor beams ended as the cow left the feeder and the gate was closed. For each bin visit, the monitoring system recorded the animal ear tags, initial and final times, and weight, and calculated the duration and feed intake. For the purposes of this validation experiment, we focused our observations on 8 feed bins.

\section{Animal and diet}

Eight Chinese Holstein non-lactating dairy cows were selected for subsequent three experiments. Cows were fed ad libitum a TMR consisting of $25 \%$ corn silage, $25 \%$ oat grass, $29 \%$ corn grain, $5 \%$ wheat bran, $12 \%$ soybean meal and $4 \%$ premix on a DM basis. The DM of the TMR was $486 \mathrm{~g}$ per $\mathrm{kg}$, and the chemical composition of the TMR was $127 \mathrm{~g}$ of CP, $467 \mathrm{~g}$ of NDF, $267 \mathrm{~g}$ of ADF per $\mathrm{kg}$ of TMR (DM basis). Gross energy in TMR was $15.9 \mathrm{MJ} / \mathrm{kg}$ TMR. Cows were housed individually in pens $(2.0 \times 1.6 \mathrm{~m}$; width $\times$ length $)$ with 3 rail sides $(1.5 \mathrm{~m}$ high $)$ and were fed twice daily at 0800 and $1600 \mathrm{~h}$, and had free access to clean water.

\section{Experimental Design}

The first experiment was to investigate the 10-h distribution of feeding behavior in cows after morning feeding by using infra-red camera (Haier, model WSC-580W). We recorded $10 \mathrm{~h}$ (08:00-18:00) for 10 consecutive days after the commencement of morning fresh feed provided, and the afternoon feeding started at 16:00. All data was saved in the memory card for the subsequent analysis of visit. The eating visit was defined as the behavior that the head of the animal was in the feed bin with corresponding head lift and jaw movement [13]. The other visits were non-eating, which was characterized as the behavior that the head of the animal was in the feed bin without contacting with feed and jaw movement. All activities were noted and recorded using the on-screen timer. Time spent on each visit activity was expressed as total seconds per 10-h measured period.

The second experiment was to investigate effect of response times in monitoring system on accuracy of recorded feed intake by comparing with direct weighting. Five treatments included response time set at $0.3,3,6,12$ and $24 \mathrm{~s}$ after triggered by the cow. We recorded 10-h (08:00-18:00) feed intake for 2 consecutive days after the commencement of morning fresh feed provided, and the afternoon feeding was also started at 16:00. The monitoring system recorded the duration of each visit by comparing start- and end-time of each visit, and feed intake of each visit by comparing start- 
and end-weight of each visit. The recorded feed intake $(\mathrm{kg} / 10 \mathrm{~h})$ was calculated by summing the feed intake of each visit, while actual feed intake was calculated by the difference between feed provided and residual feed in the bin.

The third experiment was to investigate effect of excluding the data of time interval after response time on feed intake and visiting behaviors recorded by the monitoring system. We also recorded 10-h (08:00-18:00) feeding behavior and feed intake for 2 consecutive days after the commencement of morning fresh feed provided, when response time in monitoring system was set at $0.3 \mathrm{~s}$. These 10-h feeding behaviors were also recorded in video by using infra-red camera. The data obtained in monitoring system was firstly analyzed to calculate number and duration of eating and non-eating visits, and feed intake of each visit, which were further used to discard the corresponding data of time interval after response time with help of video. Four time intervals included 3, 6, 12 and $24 \mathrm{~s}$ after response time. The 10-h feed intake was calculated by summing the feed intake of all eating visit.

\section{Statistical analysis}

Statistical analysis was performed using SPSS 21.0 software (SPSS Inc., Chicago, IL, USA). For the data of first experiment, association between each recorded feed intake and eating visit duration was evaluated by using linear regression model. For the data of second experiment, we used mixed linear model, which included calculated method as a fixed effect ( $i=2$, actual and recorded feed intake) and dairy cow as the random effect $(j=8,1,2,3,4,5,6,7$ and 8). For the data of third experiment, we also mixed linear model, which included time interval as fixed effect ( $i=5 ; 0.3$, $3,6,12$ and $24 \mathrm{~s})$, dairy cow $(j=8,1,2,3,4,5,6,7$ and 8$)$ as the random effect, day as the repeated measurement. Statistical significance was declared at $P \leq 0.05$, and a tendency towards significance was declared at $0.05<P \leq 0.10$.

\section{Results And Discussion}

The visiting activity included eating and non-eating visits. Cows tended to have relatively larger number of eating visits (894) than non-eating visits (436) by directly observing the visits of 8 dairy cows for 10-day period (Fig. 1A and B).

Furthermore, eating visits were mainly distributed after fresh feed provided, and the rate of eating visit exhibited as fast increase after morning feeding and then gradually decrease until afternoon feeding (Fig. 1C). The rate of non-eating visits showed an opposite pattern in comparison with that of eating visits, and had the lowest value when fresh feed was provided (Fig. 1D). These results clearly indicate that feeding strategy can greatly influence distribution of visit behaviors in dairy cow.

Most of eating visits had duration larger than $24 \mathrm{~s}$, which accounted for about $99.0 \%$ of total eating visits (Fig. 1A and Table 1). A greater number of non-eating visits had duration less than $24 \mathrm{~s}$, which accounted for $65.3 \%$ of the noneating visits (Fig. 1B and Table 1). These results indicated that response time with less than $24 \mathrm{~s}$ may have little effect on the accuracy of recording the number of eating visits, but can have great influence on the accuracy of recording the number of non-eating visits. 
Table 1

Summary of the number and duration of visits in dairy cows measured by 10 consecutive days $(n=8)$

\begin{tabular}{|lccccc|}
\hline Item & \multicolumn{3}{c|}{ Visit duration (s/visit) } & & \\
\cline { 2 - 6 } & $\leq 3$ & $\leq 6$ & $\leq 12$ & $\leq 24$ & $>24$ \\
\hline Number (\% of total) & & & & & \\
\hline Eating visit & 0.27 & 0.36 & 0.36 & 0.98 & 99.0 \\
\hline Non-eating visit & 11.7 & 29.9 & 48.4 & 65.3 & 34.7 \\
\hline Total visit & 4.03 & 10.1 & 16.1 & 22.1 & 77.9 \\
\hline Duration (\% of total) & & & & \\
\hline Eating visit & $<0.01$ & $<0.01$ & $<0.01$ & 0.01 & 99.99 \\
\hline Non-eating visit & 0.51 & 2.16 & 5.28 & 10.8 & 89.2 \\
\hline Total visit & 0.01 & 0.06 & 0.15 & 0.32 & 99.7 \\
\hline
\end{tabular}

Feed intake is affected by eating duration [14], feeding space [15], social feeding environment [16], temperament and dominance [17]. However, visit duration is reported to be the major factor to influence feed intake and can be used to predict feed intake [14]. In our study, the duration of eating visit was strongly and positively correlated with feed intake $\left(r^{2}=0.67 ; P<0.001\right.$, Fig. 2). Although response time had little influence on the duration of eating visit, it greatly affected the recording of feed intake. Increasing response time had quadratic effect on feed intake recorded by the monitoring system, with the greatest difference occurred at $6 \mathrm{~s}$ of response time by comparing with the actual feed intake. Increasing response time was always accompanied with missing some value of feed intake and increasing rate of accidental touching of bin bottom by cattle, which were the potential causes of inaccuracy of feed intake recorded by monitoring system.

The data of recorded feed intake and visiting behavior were then further investigated by excluding corresponding data of time interval $(3,6,12$ and $24 \mathrm{~s})$ after that response time was set as $0.3 \mathrm{~s}$. Increasing time interval linearly increased $(P<0.01)$ mean, median feed intake per visit and 10-h feed intake. Such changes in 10-h feed intake was caused by missing some short eating visits, which was further upheld by increase in minimum feed intake per visit and reduction in number and duration of eating visit. Although increasing time interval had great influence on minimum feed intake per visit $(15.2 \%)$, the extent of influence on 10 -h feed intake $(<0.1 \%)$ and eating visit $(<5 \%)$ seemed to be insignificant. On the other hand, increasing time interval greatly decreased the number $(>50 \%)$ and duration ( $>10 \%)$ of non-eating visit. These results further uphold that these missing some data cannot be major factor to influence on feed intake, but help to exclude non-eating visits. We suspected that the changes in feed intake caused by increasing response time may be due to accidental touching of bin bottom by cows, although further verification are still needed. 
Table 2

Comparison between feed intake measured by direct weighing and the monitoring system varied in five different response times $(\mathrm{n}=8)$

\begin{tabular}{|c|c|c|c|c|c|}
\hline \multirow[t]{2}{*}{ Respond time (s) ${ }^{1}$} & \multicolumn{2}{|c|}{ Feed intake (kg/10 h) } & \multirow[t]{2}{*}{ Difference $^{2}(\%)$} & \multirow[t]{2}{*}{ SEM } & \multirow[t]{2}{*}{$P$-value } \\
\hline & Direct weighing & Monitoring system & & & \\
\hline 0.3 & 26.2 & 26.3 & 1.44 & 0.04 & 0.054 \\
\hline 3 & 24.8 & 27.6 & 13.1 & 0.59 & 0.01 \\
\hline 6 & 23.5 & 28.6 & 22.8 & 0.66 & 0.001 \\
\hline 12 & 23.9 & 27.1 & 17.7 & 0.57 & 0.005 \\
\hline 24 & 24.8 & 26.1 & 8.28 & 0.35 & 0.04 \\
\hline \multicolumn{6}{|c|}{$\begin{array}{l}{ }^{1} \text { Response time was time period set between measurement and trigger of the presence of a cow in monitor syster } \\
{ }^{2} \text { Calculated by the equation of |Monitoring system - Direct weighing|* } 100 \% / \text { Direct weighing. }\end{array}$} \\
\hline
\end{tabular}


Table 3

Effects of excluding the data of time interval after response time on feed intake and visiting behaviors in dairy cattle (n = 8)

\begin{tabular}{|c|c|c|c|c|c|c|c|c|c|}
\hline \multirow[t]{3}{*}{ Item } & \multicolumn{5}{|c|}{ Feed intake } & \multicolumn{2}{|c|}{ Eating visit } & \multicolumn{2}{|c|}{ Non-eating visit } \\
\hline & \multirow{2}{*}{$\begin{array}{l}\text { Total } \\
(\mathrm{kg} / 10 \\
\mathrm{h})\end{array}$} & Mean & Median & Maximum & Minimum & \multirow{2}{*}{$\begin{array}{l}\text { Times } \\
\text { (n/10h) }\end{array}$} & \multirow{2}{*}{$\begin{array}{l}\text { Duration } \\
\text { (s/10h) }\end{array}$} & \multirow{2}{*}{$\begin{array}{l}\text { Times } \\
(\mathrm{n} / 10 \mathrm{~h})\end{array}$} & \multirow{2}{*}{$\begin{array}{l}\text { Duration } \\
\text { (s/10h) }\end{array}$} \\
\hline & & \multicolumn{4}{|c|}{ (kg / visit) } & & & & \\
\hline \multicolumn{10}{|c|}{ Time interval (s) } \\
\hline Control $^{1}$ & $26.3^{b}$ & $2.79^{a}$ & $1.50^{\mathrm{a}}$ & 9.67 & $0.38^{a}$ & $11.5^{\mathrm{b}}$ & $10186^{b}$ & $8.25^{d}$ & $388^{c}$ \\
\hline 3 & $26.3^{b}$ & $2.79^{a}$ & $1.50^{\mathrm{a}}$ & 9.67 & $0.38^{a}$ & $11.5^{\mathrm{b}}$ & $10186^{b}$ & $5.75^{\mathrm{C}}$ & $382^{c}$ \\
\hline 6 & $26.3^{b}$ & $2.81^{a}$ & $1.51^{\mathrm{ab}}$ & 9.67 & $0.40^{\mathrm{ab}}$ & $11.4^{\mathrm{b}}$ & $10185^{b}$ & $4.56^{b c}$ & $376^{a b}$ \\
\hline 12 & $26.3^{a b}$ & $2.83^{a b}$ & $1.52^{\mathrm{ab}}$ & 9.67 & $0.42^{\mathrm{ab}}$ & $11.3^{\mathrm{ab}}$ & $10183^{b}$ & $3.31^{\mathrm{ab}}$ & $366^{b}$ \\
\hline 24 & $26.3^{a}$ & $2.87^{b}$ & $1.53^{b}$ & 9.67 & $0.44^{\mathrm{b}}$ & $11.1^{\mathrm{a}}$ & $10180^{a}$ & $2.13^{a}$ & $345^{\mathrm{a}}$ \\
\hline SEM & 0.003 & 0.018 & 7.1 & 0.0 & 0.016 & 0.08 & 1.0 & 0.558 & 5.2 \\
\hline $\begin{array}{l}\text { Difference } \\
(\%)^{2}\end{array}$ & 0.04 & 3.05 & 2.13 & - & 15.2 & 3.48 & 0.06 & 74.2 & 11.1 \\
\hline \multicolumn{10}{|l|}{$P$ value } \\
\hline Effect & 0.01 & 0.01 & 0.02 & - & 0.04 & 0.003 & 0.002 & $<0.001$ & $<0.001$ \\
\hline Linear & 0.001 & 0.001 & 0.001 & - & 0.004 & $<0.001$ & $<0.001$ & $<0.001$ & $<0.001$ \\
\hline Quadratic & 0.17 & 0.23 & 0.40 & - & 0.70 & 0.12 & 0.04 & 0.23 & 0.10 \\
\hline
\end{tabular}

\section{Conclusions}

Setting proper response time is critical for obtain feeding behaviors and feed intake for the monitoring system. To our knowledge, this study firstly indicates that an immediate response ( $0.3 \mathrm{~s}$ of response time) after triggered by the cows help to record actual feed intake, but can also have a lot of non-eating visits. Increasing response time helps to decrease the recording of non-eating visits, but can overestimate feed intake.

\section{Declarations}

\section{Ethics approval and consent to participate}

All animal procedures used in this study were reviewed and approved by the Animal Care Committee, Institute of Subtropical Agriculture, the Chinese Academy of Sciences, Changsha, China. 


\section{Consent for publication}

Not applicable

\section{Availability of data and materials}

All data generated or analyzed during this study are included in this published article.

\section{Competing interests}

The authors declare no competing interests.

\section{Funding}

This work was supported by National Natural Science Foundation of China (Grant No. 31922080), National Key Research and Development Program of China (Grant No. 2018YFD0501800 and 2016YFD0500504), China Agriculture Research System (Grant No. CARS-36). The authors declare that they have no conflict of interest.

\section{Authors' contributions}

RW, CG, MW, XZ ZM and DW designed research; RW, CG, ZW, ZL and SG conducted research; RW and MW analyzed data; RW wrote the paper; MW and ZL revised the paper. All authors read and approved the final manuscript and take full responsibility for the final content.

\section{Acknowledgements}

Not applicable.

\section{References}

1. Halachmi I, Ben Meir Y, Miron J, Maltz E. Feeding behavior improves prediction of dairy cow voluntary feed intake but cannot serve as the sole indicator. Animal. 2016; 10:1501-6.

2. Oliveira Junior BR, Silper BF, Ribas MN, Machado FS, Lima JAM, Cavalcanti LFL, et al. Tick-borne disease is associated with changes in feeding behavior in automatically fed weaned dairy calves. J Dairy Sci. 2018; 101:11256-61.

3. Werner J, Umstatter C, Leso L, Kennedy E, Geoghegan A, Shalloo L, et al. Evaluation and application potential of an accelerometer-based collar device for measuring grazing behavior of dairy cows. Animal. 2019; 13:2070-9.

4. Achour B, Belkadi M, Filali I, Laghrouche M, Lahdir M. Image analysis for individual identification and feeding behaviour monitoring of dairy cows based on Convolutional Neural Networks (CNN). Biosyst Eng. 2020; 198:31-49.

5. Bloch V, Levit H, Halachmi I. Assessing the potential of photogrammetry to monitor feed intake of dairy cows. J Dairy Res. 2019; 86:34-9.

6. Mirzaei-Alamouti H, Akbari-Pabandi K, Mansouryar M, Sirjani MA, Cieslak A, Szumacher-Strabel M, et al. Effects of feeding frequency and oil supplementation on feeding behavior, ruminal fermentation, digestibility, blood 
metabolites, and milk performance in late-lactation cows fed a high-forage diet. J Dairy Sci. 2020; 103:11424-38.

7. Nemati M, Hashemzadeh F, Ghorbani GR, Ghasemi E, Khorvash M, Ghaffari MH, et al. Effects of substitution of beet pulp for barley or corn in the diet of high-producing dairy cows on feeding behavior, performance, and ruminal fermentation. J Dairy Sci. 2020; 103:8829-40.

8. Chizzotti ML, Machado FS, Valente EEL, Pereira LGR, Campos MM, Tomich TR, et al. Technical note: Validation of a system for monitoring individual feeding behavior and individual feed intake in dairy cattle. J Dairy Sci. 2015; 98:3438-42.

9. Oliveira BR, Ribas MN, Machado FS, Lima JAM, Cavalcanti LFL, Chizzotti ML, et al. Validation of a system for monitoring individual feeding and drinking behaviour and intake in young cattle. Animal. 2018; 12:634-9.

10. Merenda VR, Marques O, Miller-Cushon EK, DiLorenzo N, Laporta J, Chebel RC. Technical note: validation of a system for monitoring individual behavior in beef heifers. J Anim Sci. 2019; 97:4732-6.

11. Chapinal N, Veira DM, Weary DM, von Keyserlingk MAG. Technical note: Validation of a system for monitoring individual feeding and drinking behavior and intake in group-housed cattle. J Dairy Sci. 2007; 90:5732-6.

12. Tolkamp BJ, Schweitzer DPN, Kyriazakis I. The biologically relevant unit for the analysis of short-term feeding behavior of dairy cows. J Dairy Sci. 2000; 83:2057-68.

13. Arowolo MA, Yang S, Wang M, He JH, Wang C, Wang R, et al. The effect of forage theoretical cut lengths on chewing activity, rumen fermentation, dissolved gases, and methane emissions in goats. Anim Feed Sci Tech. 2020; 263:114454.

14. Nielsen BL. On the interpretation of feeding behaviour measures and the use of feeding rate as an indicator of social constraint. Appl Anim Behav Sci. 1999; 63:79-91.

15. Yildirir M, Das G, Lambertz C, Gauly M. Feeding, resting and agonistic behavior of pregnant boer goats in relation to feeding space allowance. Ann Anim Sci. 2019; 19:1133-42.

16. Mainardes GA, DeVries TJ. Effect of social feeding environment on the feeding behaviour of dairy cows and their willingness to consume a novel feed. Appl Anim Behav Sci. 2016; 185:23-9.

17. Llonch P, Somarriba M, Duthie CA, Troy S, Roehe R, Rooke J, et al. Temperament and dominance relate to feeding behaviour and activity in beef cattle: implications for performance and methane emissions. Animal. 2018;

12:2639-48.

\section{Figures}



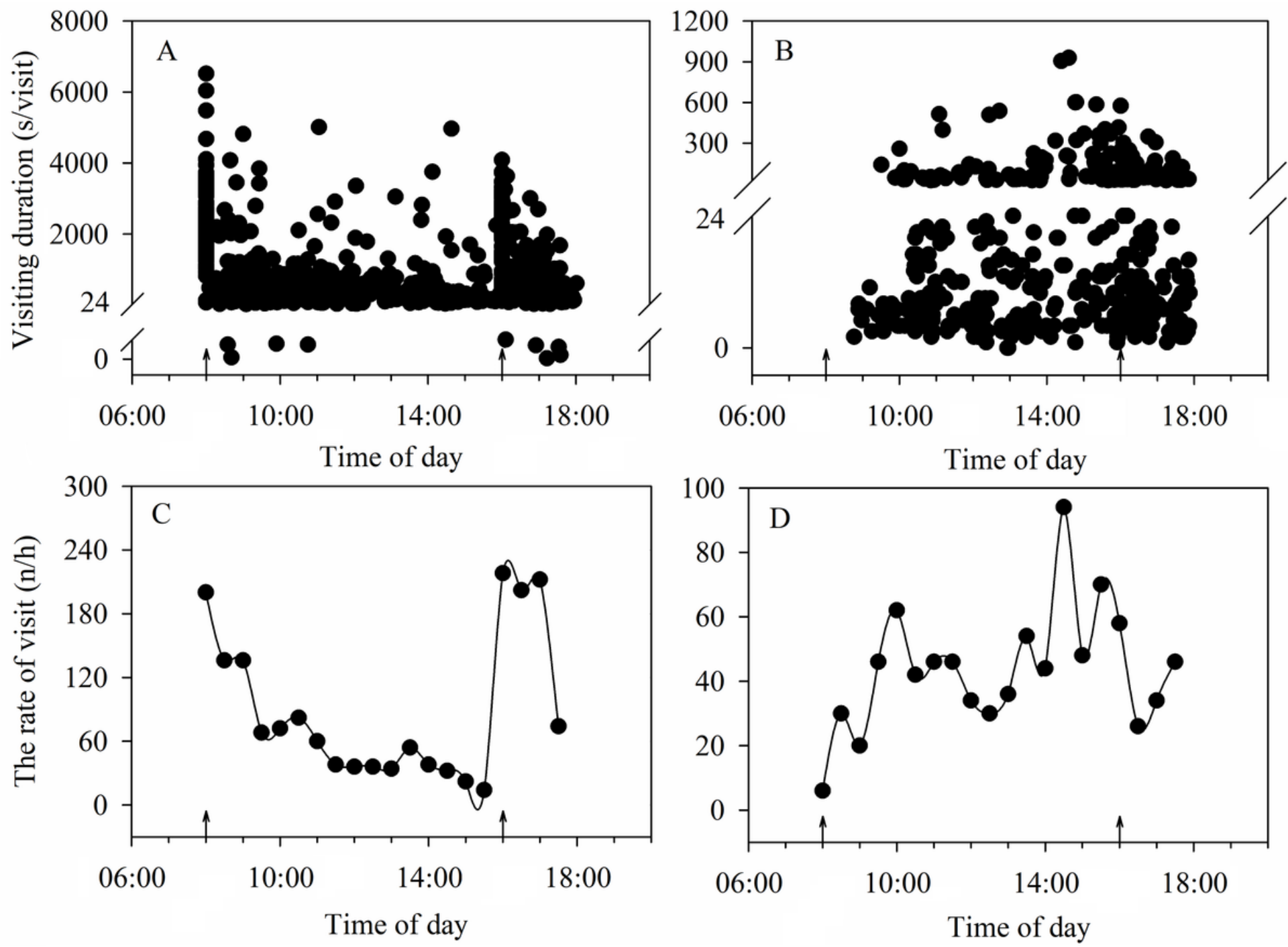

Figure 1

Distribution of visiting behavior during the 10-h period after morning feeding in dairy cows measured by 10 consecutive days $(n=8)$. Arrow is the time when the fresh feeds are provided. A, eating visit with 894 points; $B$, non-eating visit with 436 points; $C$, eating visits; $D$, non-eating visits. 


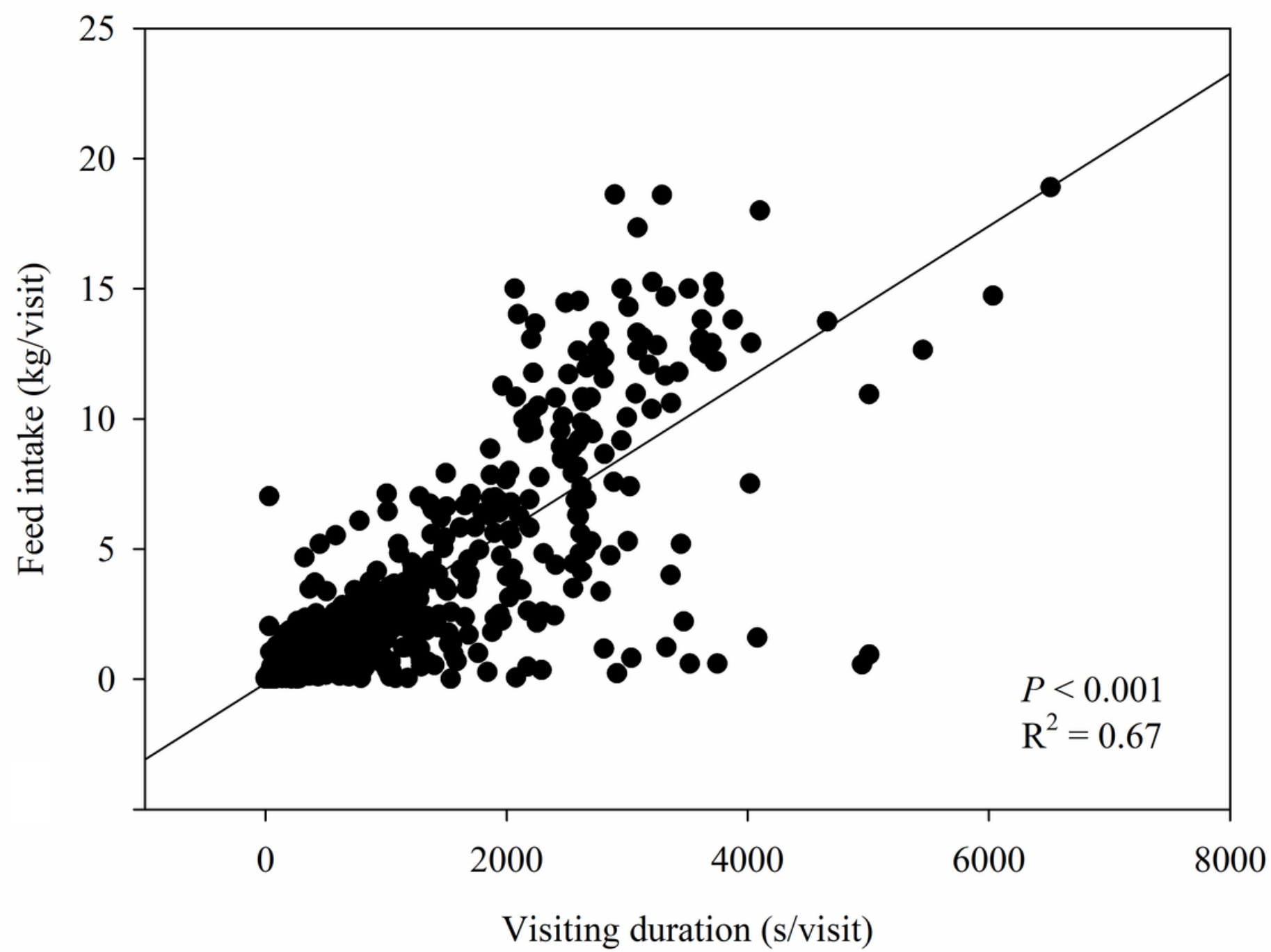

Figure 2

Relationships between feed intake (kg/visit) and visiting duration ( $\mathrm{s} / \mathrm{visit})$ in dairy cows $(\mathrm{n}=8, \mathrm{~N}=894)$. The line is the best linear regression line. Each point represents data of per visit per cow. 